B3

J. bio-sci. 14: 69-72, 2006

ISSN 1023-8654

\title{
DEFORMITIES PRODUCED BY SOME PLANT POWDERS IN RHYZOPERTHA DOMINICA (F.) (COLEOPTERA: BOSTRICHIDAE)
}

\author{
Nur Mohal1', W Islam, K A M S H Mondal and S Parween \\ Institute of Biological Sciences, 'Department of Zoology \\ University of Rajshahi, Rajshahi 6205, Bangladesh \\ Rajshahi Govt. New Degree College, Rajshahi 6000, Bangladesh
}

\begin{abstract}
The larval feeding of Rhyzopertha dominica (F.) on whole wheat grains treated with dry leaf powder of Murrya paniculata L., Jatropha curcas L. (Jack), Datura metel L., Eucalyptus camaldulensis Dehn. and Virtex negundo L. and seed powder of Nigella sativa L. produced abnormalities in larval, pupal and adult stages at doses $2.5,5$ and $10 \mathrm{mg} / \mathrm{g}$ in case of all leaf powder treatments and the effect was more distinct at higher doses. Compared to leaf powders seed powder of $N$. sativa was more effective, however, the deformities responded in the larval, pupal and adult stages were more or less similar in case of all the plant products. The percentages of deformities produced differed significantly among the doses $(P<0.001, F=5.10)$ of different plants $(P<0.001, F=3.89)$.
\end{abstract}

Key words: Deformities, R. dominica, plant powders.

\section{Introduction}

Presence of exogenous materials in food very often interrupts normal metamorphosis and may produce different types of deformed individuals at any stage of insect life. Feeding on plant material treated food produces different kinds of deformities in insects (Nawrot et al. 1987.)

Plant oils have reported to produce deformed characters in insects (Jilant et al. 1988, Subrahmanyan and Rao 1993). Similarly, leaf powders also produced abnormalities in Tribolium (Rahman 1992). Azadirachtin treatment interfered with the normal development of the larvae of Japanese beetle (Ladd et al. 1984). Juvenile hormone activity mimicking compounds were isolated from sweet basil oil (Bowers and Nishida 1980) and marigold oil (Saxena and Srivastava 1973), which produced deformities in bug species.

In the present work attempt was taken to observe any abnormalities produced in the lesser grain borer, Rhyzopertha dominica $(\mathrm{F})$ due to feeding on food mixed with seed/leaf powders of some plants.

\section{Materials and methods}

\section{Plant powders used}

Dry leaf powder of Murrya paniculata L., Jatropha curcas L. (Jack), Datura metel L., Eucalyptus camaldulensis Dehn. and Vitex negundo $\mathrm{L}$. at a dose of $2.5,5$ and $10 \mathrm{mg} / \mathrm{g}$ were mixed separately with wheat grains. Seed powder of Nigella sativa L. were used at a dose 1, 2 and $4 \mathrm{mg} / \mathrm{g}$.

•Corresponding author: e-mail: mwislam2001@yahoo.com. 


\section{Experimentation}

One hundred newly hatched larvae of $R$. dominica were released on each dose of each plant powder treated wheat. Similar number of neonates was released on untreated wheat as control. After emergence, the adults were observed carefully, while types of deformities were recorded and the numbers of deformed adults were noted. The grains from which adults were not emerged, were dissected carefully, and the life stage of the insect inside the grain were examined for abnormal characteristics.

The experiments were replicated four times four each dose/each plant/ and control. The experiments were conducted at room temperature $30 \pm 1{ }^{\circ} \mathrm{C}$.

\section{Results and Discussion}

Larval feeding on the treated wheat produced abnormal characters at larval, pupal and adult stages. Highest percentage of deformity was found against $N$. sativa seed powder compared to other plant products (Table1), which differed significantly among the doses $(P<0.001, F=5.10)$ of different plants $(P<0.001, F=3.89)$

Table 1. Percentage of larval, pupal and adult deformities in $R$. dominica feeding on untreated and treated wheat grains with plant materials.

\begin{tabular}{|c|c|c|c|c|c|c|c|c|c|}
\hline \multirow{2}{*}{$\begin{array}{l}\text { Treatments } \\
\text { Control }\end{array}$} & \multirow[t]{2}{*}{$\begin{array}{l}\text { Doses } \\
(\mathrm{mg} / \mathrm{g})\end{array}$} & \multirow{2}{*}{$\begin{array}{l}\text { No. of larva } \\
\text { used } \\
\text { (1st instar) }\end{array}$} & \multicolumn{2}{|c|}{$\begin{array}{l}\text { Deformed } \\
\text { larvae }\end{array}$} & \multicolumn{2}{|c|}{$\begin{array}{l}\text { Deformed } \\
\text { Pupae }\end{array}$} & \multicolumn{2}{|c|}{$\begin{array}{l}\text { Deformed } \\
\text { adults }\end{array}$} & \multirow{2}{*}{$\begin{array}{l}\text { Total } \\
\text { deformed } \\
\text { individuals } \\
(\%)\end{array}$} \\
\hline & & & No. & $(\%)$ & No. & $(\%)$ & No. & $(\%)$ & \\
\hline \multirow[t]{3}{*}{ N. Sativa } & 10 & 100 & 8 & $8 c$ & 4 & $4^{a b}$ & 4 & $4^{a b}$ & 16 \\
\hline & 20 & 100 & 14 & $14^{b}$ & 4 & $4^{\mathrm{ab}}$ & 5 & $5^{a}$ & 23 \\
\hline & 40 & 100 & 19 & $19 a$ & 5 & $5^{a}$ & 6 & $6^{a}$ & 30 \\
\hline \multirow[t]{3}{*}{ M. Paniculata } & 25 & 100 & 0 & 0 & 3 & $3^{b}$ & 4 & $4^{a b}$ & 7 \\
\hline & 50 & 100 & 0 & 0 & 4 & $4^{a b}$ & 5 & $5^{\mathrm{a}}$ & 9 \\
\hline & 100 & 100 & 0 & 0 & 5 & $5^{b}$ & 5 & $5^{a}$ & 10 \\
\hline \multirow[t]{3}{*}{ J. curcas } & 25 & 100 & 0 & 0 & 3 & $3^{a}$ & 3 & $3^{b}$ & 6 \\
\hline & 50 & 100 & 1 & $1^{e}$ & 4 & $4^{\mathrm{ab}}$ & 4 & $4^{\mathrm{ab}}$ & 9 \\
\hline & 100 & 100 & 1 & $1 \mathrm{e}$ & 4 & $4^{\mathrm{ab}}$ & 4 & $4^{\mathrm{ab}}$ & 9 \\
\hline \multirow[t]{3}{*}{ E. camaldulensis } & 25 & 100 & 0 & 0 & 3 & $3^{b}$ & 3 & $4^{\mathrm{ab}}$ & 6 \\
\hline & 50 & 100 & 1 & $1^{e}$ & 4 & $4^{a b}$ & 4 & $4^{\mathrm{ab}}$ & 9 \\
\hline & 100 & 100 & 1 & $1 \mathrm{e}$ & 5 & $5^{a}$ & 5 & $5^{\mathrm{a}}$ & 11 \\
\hline \multirow[t]{3}{*}{ D. metel } & 25 & 100 & 0 & 0 & 3 & $3^{b}$ & 4 & $4^{\mathrm{ab}}$ & 7 \\
\hline & 50 & 100 & 2 & $2^{\text {de }}$ & 5 & $5^{a b}$ & 5 & $5^{a}$ & 8 \\
\hline & 100 & 100 & 3 & $3^{d}$ & 6 & $6^{a}$ & 6 & $6^{a}$ & 11 \\
\hline \multirow[t]{3}{*}{ V. negundo } & 25 & 100 & 0 & 0 & 3 & $3^{b}$ & 3 & $4^{a b}$ & 7 \\
\hline & 50 & 100 & 2 & $2^{\text {de }}$ & 5 & $5^{a b}$ & 5 & $5^{a}$ & 12 \\
\hline & 100 & 100 & 3 & $3^{d}$ & 6 & $6^{a}$ & 6 & $6^{a}$ & 15 \\
\hline
\end{tabular}

Note: Means within the columns followed by the same letters are not significantly $(P<0.05)$ different (DMRT). In the following manner the stage wise deformed characters were recorded. 


\section{A Larval deformities}

i. Size: larvae in the treated grain were smaller than those in the untreated grain

ii. Colour: the off-white colour of the larvae changed to yellow (M. paniculata), light brown (J. curcas and $E$ camaldulensis) and deep yellow (V. negundo)

iii. Outgrowth: an abnormal outgrowth developed at the posterior region of the larval body

\section{B Pupal deformities}

i. Size: pupae developed in treated wheat were undersized

ii. Body shape and wing pads: most of the pupae were with humped abdomen; pupal wing pads were short and less sclerotized in $J$. curcas and $D$. metel treated grains.

iii. Cephalic character: a number of pupae were with deformed head region.

\section{Adult deformities:}

i. Size: adults emerged from treated grains were smaller than untreated ones and their weight was reduced.

ii. Abdomen: some of the adults were depressed and some were with humped backs.

iii. Symmetry: proper bilateral symmetry was lost to some extent in the adults of treated grains. These adults failed to remain at normal position and were less motile.

iv. Wing: most of the treated adults were with elytral deformities like, broken elytra, elytra failed to appose each other in some adults the membranous wings remained stretched and unfolded, often curled.

v. Ovipositor: in a number of treated adults, the ovipositor was protruded out of the genetilia.

In the present experiment seed powder of $N$. sativa was found to produce more deformed individuals than produced by the leaf powder of other plants. Moreover, deformed larvae were produced in each treatment except M. paniculata and the normal colour of the larvae was changed.

Presence of exogenous materials in food, contact with chemicals and radiation at any stage generally interrupt normal metamorphosis in insects producing varying types of deformed individuals at any stage of their life. Formation of the deformed characters usually depends on the mode of action of the plants (Nawrot et al. 1987). The most pronounced effect of treatment in the present study was found on the adults and all the deformed characters might be resulted due to less sclerotization of the adult body.

Elytral deformities were also found in Tribolium castaneum (Herbst) feeding on flour treated with leaf dust of Dhutura (D. metel) and Neem (Azadirachta indica) (Rahman 1992).

In the present study all the tested materials produced similar deformed individuals at larval, pupal and adult stages of $R$. dominica. The highest percentage of deformities was obtained in case of the seed powder of $N$. sativa treated wheat and the lowest in case of J. curcas treated wheat. The deformed larvae and pupae were failed to metamorphose into adults. The undersized and underweight adults with deformed wings and protruded ovipositor were found unable to mate properly, and also failed to survive long. 


\section{Acknowledgements}

The first author thanks the Ministry of Education, Peoples Republic of Bangladesh for providing study leave and the University Grants commission, Bangladesh for funding. Thanks to Professor A T M Nadiruzzaman, Department of Botany, Rajshahi University, Bangladesh for identifying the plants.

\section{References}

Bowers W S and Nishida R (1980) Juvocimenes Potent juvenile hormone mimics from sweet basil. Science 209: 1030-1032.

Jilani G, Saxena R C and Rueda B P (1988) Repellent and growth inhibiting effects of turmeric oil, sweet flag oil, neem oil and "Margoson-O" on red flour beetle (Coleoptera : Tenebrionidae). J. Econ. Ent. 81: 1226-1230.

Ladd Jr T C, Warthen Jr J D and Klein M G (1984) Japanese beetle (Coleoptera: Scarabaeidae) : The effects of azadirachtin on the growth and development of the immature forms. J. Econ. Ent. 77: 903-905

Nawrot J, Harmatha J and Bloszyk E (1987) Secondary plant metabolites with anti feeding activity and their effects on some stored product insects. Proc. $4^{\text {th }}$ Inter. Works Conf. on Stored Prod. Prot. 21-26 September 1986 ( E Donahaye and S Navarro eds. ) Tel Aviv, Israel. pp. 591-597

Rahman A S M S (1992) Combined action of Pirimiphos-methy!, synthetic methylquinone and botanicals or Tribolium castaneum Duval. Ph D Thesis, University of Rajshahi, Bangladesh, 232 pp.

Saxena B P and Srivastava J B (1973) Tagetes minuta Linn. Oil- A new source of juvenile hormone mimicking substance. Indian J. Exp. Biol. 11:56-58

Subrahmanyam B and Rao P J (1993) Biological effects of certain oils and terpene fractions of plant origin on insects. Proc. World Neem Conf. India 1993. Neem and Environment 2 : 1029-1035. Oxford \& IBH Publ. Co. Pvt. Ltd. 